\title{
IMUNOTERAPIAS NO TRATAMENTO DA COVID-19
}

Immunotherapies as a treatment for Covid-19

Imunoterapias en el tratamiento de la Covid - 19

Beatriz Mella Soares Pessoa ${ }^{1}$, Cecília Tizatto Barroso ${ }^{1}$, David José Thaise Farias Rodrigues ${ }^{1}$, Maria Cristina Dos-Santos ${ }^{2}$, Antonio Luiz Boechat*2

${ }^{1}$ Programa de Educação Tutorial PET Medicina, Faculdade de Medicina, Universidade Federal do Amazonas, Manaus, Brasil.

${ }^{2}$ Disciplina de Imunologia Médica, Laboratório de Imunoquímica, Instituto de Ciências Biológicas, Universidade Federal do Amazonas, Manaus, Brasil.

*Correspondência: Laboratório Imunoquímica, Instituto de Ciências Biológicas, Setor Sul Mini-campus, Universidade Federal do Amazonas, Av. General Rodrigo Otávio Jordão Ramos, 1200, Coroado I, Manaus-AM, Brasil. CEP:69.067-005.e-mail alboechat@ufam.edu.br.

\section{RESUMO}

A COVID-19 é uma doença causada pelo novo coronavírus e se tornou-se ameaça mundial pouco tempo após seu surgimento na cidade chinesa de Wuhan. Desde Dezembro de 2019, diversas pesquisas estão sendo realizadas com o propósito de conter a disseminação do vírus e de se obter medidas de tratamento úteis no combate à pandemia. Com isso, o presente estudo volta-se para a análise das novas metodologias de caráter terapêutico que estão sendo desenvolvidas mundialmente para o tratamento e prevenção da COVID-19. A presente revisão bibliográfica foi realizada com os dados obtidos nas seguintes bases: SciELO, Medline, Scopus, Up to Date, dentre outros recursos atuais e relevantes para a temática, que foram publicados no primeiro trimestre do ano de 2020. Com este levantamento foram identificadas diversas abordagens de tratamento ainda em desenvolvimento, com diferentes modelos, bem como mecanismo de ação de novas medidas terapêuticas e de imunização, sobretudo, as que utilizam soro, imunoglobulinas, anticorpos monoclonais, plasma de pacientes convalescentes e vacinas. O sistema de saúde mundial urge pela criação de uma vacina capaz de estabelecer a memória imunológica na população. Novos estudos mostram-se promissores em relação a essa criação, todavia, as medidas profiláticas permanecem como prioridade máxima e indispensáveis.

Palavras-chave: COVID-19, Vacinas, Pandemia.

\section{ABSTRACT}

The COVID-19 is a disease caused by the new coronavirus that became a worldwide threat shortly after its appearance in Wuhan, a Chinese city. Since December 2019, multiple researches initiatives have been carried out with the purpose of containing the spread of the virus and obtaining useful measures to fight the pandemic. Thus, the present study focuses on the analysis of new therapeutic methodologies that are being developed worldwide for the treatment and prevention of COVID-19. A bibliographic review was carried out, using databases such as SciELO, Medline, Scopus, The New England Journal of Medicine and Up to Date, among other current resources relevant to the theme, carried out and made available in the first quarter of the year 2020. Using this approach, new developing immunotherapies were identified, as well as the different models and the mechanisms of action of these new therapeutics and immunization measures, mainly, serum and immunoglobulins, monoclonal antibodies, plasma of 
convalescent patients and vaccine. That the world health system urges for the creation of a vaccine capable of establishing the immune memory in the population. New studies show that they are promising in relation to this creation, however, prophylactic measures remain a top and indispensable priority.

Keywords: COVID-19, Vaccines, Pandemic.

\section{RESUMEN}

La COVID-19 us una enfermedad causada por el nuevo coronavirus y se convirtió en una amenaza mundial poco después de su aparición en Wuhan, una ciudad china. Desde diciembre de 2019, se han realizado múltiples encuestas con el fin de frenar la propagación del virus y obtener medidas útiles para combatir la pandemia. Por lo tanto, el presente estudio se centra en el análisis de nuevas metodologías terapéuticas que se están desarrollando en todo el mundo para el tratamiento y prevención de COVID-19. Se realizó una revisión bibliográfica, utilizando bases de datos como SciELO, Medline, Scopus, Up to Date, entre otros recursos actuales relevantes para el tema, realizados $y$ disponibles en el primer trimestre del año 2020. Con este enfoque se identificaron el desarrollo, los diferentes modelos y el mecanismo de acción de nuevas medidas terapéuticas y de inmunización, sobre todo, de suero e inmunoglobulinas, anticuerpos monoclonales, plasma de pacientes convalecientes y vacuna. Se concluye que el sistema de salud mundial insta a la creación de una vacuna capaz de establecer la memoria inmune en la población. Nuevos estudios son prometedores en relación con esta creación, sin embargo, las medidas profilácticas siguen siendo una prioridad principal e indispensable.

Palabras clave: COVID-19, Vacunas, Pandemia.

\section{INTRODUÇÃO}

Em dezembro do ano de 2019, em Wuhan, uma cidade na província de Hubei, na China, surgiram os primeiros casos de infecção causados por um tipo de vírus até então desconhecido, que induzida a denominada Síndrome Respiratória Aguda Grave (SRAG), que se manifesta de maneira muito semelhante ao coronavírus causador da SARS. (ROTHAN e BYRAREDDY, 2020). O novo vírus foi denominado SARS-CoV-2 e foi isolado do lavado broncoalveolar de um paciente com SRAG atendido em Wuhan, com genoma completamente sequenciado e identificado como uma nova variedade de coronavírus (WU et al., 2020).

Essa doença altamente contagiosa, em pouco tempo, tornou-se uma ameaça global por (1) seu curso clínico variável de acordo com cada indivíduo, ao apresentar-se tanto de forma assintomática quanto mais intensas e graves; (2) alta capacidade de transmissibilidade, a qual ocorre majoritariamente pelas vias aéreas; (3) evoluir com exacerbações, algumas vezes fatais, principalmente em grupos considerados de risco. De acordo com último relatório da Organização mundial de Saúde (WHO, 2020) de 06 de abril de 2020, 1.210.956 casos foram confirmados desde o início da pandemia em dezembro de 2019, com 67.594 mortes.

Denominada COVID-19 (GUAN et al., 2019), a doença tem período médio de incubação 2-7 dias, podendo chegar até 14 dias em alguns casos (LI et al., 2020) e suas principais manifestações clínicas correspondem à febre, tosse e dispneia, as quais podem cursar, menos comumente, com náuseas e vômitos e diarreia. As Comorbidades associadas à doença grave $\mathrm{e}$ mortalidade incluem: doenças cardiovasculares, diabetes mellitus, hipertensão, doença pulmonar crônica, câncer e doença renal crônica, também inclui condições imunocomprometidas, obesidade grave (índice de massa corporal $\geq 40$ ) e doença hepática como fatores de risco em potencial para doenças graves (CENTERS FOR DISEASE CONTROL AND PREVENTION, 2019), embora dados específicos sobre os riscos associados a essas condições sejam limitados (ZHOU et al, 2020).

Tendo em vista o efeito da mobilidade humana na pandemia de Covid-19 (KRAEMER et al., 2020), 
inúmeras medidas preventivas foram tomadas, governamentais ou não, a fim de evitar o colapso dos sistemas de saúde ao redor do mundo (WANG Y et al., 2020).

Dentre essas medidas, destaca-se o desenvolvimento de novas vacinas. A imunidade ativa, obtida pela administração da vacina contra um patógeno, depende das interações entre os sistemas imunes inato e adaptativo. Uma série de tecnologias surgiram para permitir a produção de vacinas, as quais precisam de antígenos especificamente identificados, principalmente, proteicos, capazes de induzir uma resposta $\mathrm{T}$-dependente e gerar uma imunidade eficaz e duradoura. Logo, receber uma vacina é uma estratégia de simulação da defesa natural do corpo humano contra um patógeno específico e, assim, estabelecer uma memória imunológica que proteja o indivíduo de futuras infecções. Atualmente, existem várias tecnologias utilizadas para o desenvolvimento de vacinas, mas as vacinas clássicas, geralmente, são compostas por vírus ou bactérias, mortos ou atenuados ou, ainda por proteínas isoladas, conjugadas ou haptenos conjugados às proteínas, que possam ativar o sistema imune (MOSER, 2010).

Outro tipo de medida preventiva envolve imunização passiva, cujo mecanismo é a administração de anticorpos contra um agente específico com o objetivo de neutralizá-lo e impedi-lo de causar a doença. A soroterapia é utilizada quando o paciente não tem tempo hábil para produzir a sua imunidade natural e, mantê-lo exposto ao agente, pode causar-lhe sequelas irreversíveis ou até mesmo a morte. No início do século 20, soro de indivíduos convalescentes foi usado para controlar surtos de doenças virais como poliomielites e influenza (CASADEVALL e PIROFSKI, 2020). Uma metanálise de 8 estudos envolvendo 1703 pacientes durante o surto de H1N1 mostrou que os pacientes que receberam o soro tiveram menor mortalidade (LUKE et al., 2010).

Experiências com surtos anteriores, como SARS-CoV-1, mostraram que o soro convalescente pode neutralizar o vírus circulante (1) antes de infectar a célula-alvo; (2) após a lise da célula infectada e liberação de novas partículas virais. Para o vírus SARS-CoV-2, a forma de terapia passiva com anticorpos envolve neutralização da partícula viral e está atualmente sendo testada e pesquisada por diversas instituições que serão abordadas a seguir (CASADEVALL e PIROFSKI, 2020)

\section{MATERIAIS E MÉTODOS}

As informações contidas nesta revisão foram obtidas por meio de busca em plataforma de pesquisa bibliográfica, utilizado as bases SciELO, Medline, Scopus, Up-to-Date e dados mais atuais sobre o tema. As palavras-chave e estratégias de busca Imunoterapias no tratamento da COVID-19 foram: "vaccines" AND "covid-19", "antibodies" AND "covid-19", ("sera" OR "convalescent sera") AND "covid-19", "monoclonal antibodies" AND "covid-19", "immunotherapies" AND "covid-19". Os sites de registro de ensaios clínicos nacionais e internacionais consultados para identificação de ensaios clínicos registrados foram clinicaltrials.gov (Estados Unidos), ensaiosclinicos.gov.br (Brasil), chictr.org.cn (China), clinicaltrialsregister.eu (Europa).

\section{REVISÃO BIBLIOGRÁFICA}

\section{Soro e Imunoglobulinas}

A imunização passiva refere-se ao processo pelo qual ocorre a transferência direta de imunoglobulinas séricas ou linfócitos $\mathrm{T}$ específicos de um indivíduo imunizado para um não imune. Podendo 
ser de forma (1) heteróloga, com administração de anticorpos obtidos de animais imunizados (equídeos, carneiros ou lhamas) normalmente chamado de soros; (2) de forma homóloga, a partir de anticorpos provenientes do plasma humano, conhecido como gamaglobulina. Dessa forma, o receptor se torna, temporariamente, imunizado, da mesma forma que o doador, mas sem ter tido o contato direto com o antígeno (ABBAS, 2018).

Assim sendo, essa forma de imunização se apresenta como um meio relativamente rápido de se obter imunidade, sem que ocorra o processo de resposta imune ativa esperado das vacinas. No entanto, essa forma de imunidade tem como desvantagem o seu comportamento transitório devido ao clearance dos anticorpos circulantes, sendo, na prática, direcionada para a situações de emergência relacionadas como o contato com toxinas, venenos ou contra determinados microrganismos como no caso da hepatite B, citomegalovírus, tétano, raiva e toxina botulínica (CASADEVALL e PIROFSKI, 2015), além de ser utilizada, sina, em situações de descumprimento do calendário vacinal ou em pacientes imunossuprimidos (MINISTÉRIO DA SAÚDE BRASIL, 2006).

$\mathrm{Na}$ atual corrida pela busca de formas terapêuticas resolutivas para pandemia de COVID-19, empresas farmacêuticas e pesquisadores buscam formas de utilização da imunização passiva a partir do soro de pacientes recuperados ou a partir do isolamento de suas imunoglobulinas específicas. Juntamente, as atuais evidências apontam para correlações estruturais entre as proteínas virais da SARS-CoV, MERS-CoV e SARS-CoV-2 que seriam benéficas na busca pela imunização a partir do soro de pacientes recuperados de SARS ou MERS (PROMPETCHARA et al., 2020).

\section{Anticorpos Monoclonais}

Durante uma resposta imune, além de outros mecanismos humorais e celulares, diversos linfócitos B diferenciados em plasmócitos, produzem anticorpos para o combate contra um determinado antígeno. Por se tratar-se de células, que montam seus receptores na linhagem somática, com especificidade própria, interagem com diferentes determinantes antigênicos, presentes no patógeno, levando a produção anticorpos com especificidade e afinidade diferentes. Por isso, a imunização vacinal induz a ativação de vários linfócitos B, que ao expandirem os seus clones, produzem uma resposta policlonal. A terapia dos anticorpos monoclonais tem como base a produção de uma resposta imune para um único epítopo (ou determinante antigênico), oriunda de um único linfócito B. Geralmente o anticorpo monoclonal neutraliza o sítio de ligação do antígeno à célula-alvo.

Os anticorpos monoclonais são produzidos em laboratório pela fusão de um linfócito $\mathrm{B}$, produtor do anticorpo desejado à uma célula de mieloma, formando o hibridoma que se multiplicará e produzirá grandes quantidades de anticorpo. Os anticorpos produzidos serão utilizados na terapia e chamados de monoclonais, pois se originam de clones de um único linfócito $\mathrm{B}$ (MANIS, 2019).

Contra a atual pandemia do COVID-19, a Comissão Nacional de Saúde da China inclui em suas diretrizes a utilização do tocilizumab, um anticorpo monoclonal que age na inibição da via da interleucina 6 (IL-6), em pacientes graves e com níveis elevados de IL-6, consoante a essa realidade, outros dois anticorpos monoclonais, sarilumab e siltuximab, com o mesmo mecanismo de ação contra a via da IL-6, estão em fases de ensaios clínicos (MCINTOSH, 2020). Também há iniciativas para produção de anticorpos monoclonais anti-SARS-CoV-2 para neutralização direta do vírus (WANG C et al., 2020). 
Fora da China, na União Europeia um ensaio clínico busca mensurar a eficácia da utilização de anticorpos monoclonais na infecção pelo SARS-CoV2 (Quadro 1, Ref. 1), bem como nos Estados Unidos, onde há ensaios clínicos sobre a utilização de tocilizumab (Quadro 1, Ref. 2), sarilumab (Quadro 1, Ref. 3), e anti-IL-6 (Quadro 1, Ref. 4).

Quadro 1. Ensaios Clínicos com Anticorpos Monoclonais

\begin{tabular}{|c|c|c|}
\hline Ref. & Ensaios Clínicos Mencionados & Registro do Ensaio Clínico \\
\hline 1 & $\begin{array}{l}\text { Efficiency in Management Of Organ Dysfunction Associated } \\
\text { With Infection by the Novel Sars-Cov-2 Virus (Covid-19) } \\
\text { Through A personalized Immunotherapy Approach: The Escape } \\
\text { Clinical Trial }\end{array}$ & EU Clinical Trials Register \\
\hline 2 & $\begin{array}{l}\text { Cohort Multiple Randomized Controlled Trials Open-label of } \\
\text { Immune Modulatory Drugs and Other Treatments in COVID-19 } \\
\text { Patients - Tocilizumab Trial - CORIMUNO-19- TOCI } \\
\text { (CORIMUNO-TOC) }\end{array}$ & $\begin{array}{l}\text { U. S. National Library of Medicine } \\
\text { ClinicalTrials.gov }\end{array}$ \\
\hline 3 & $\begin{array}{c}\text { Cohort Multiple Randomized Controlled Trials Open-label of } \\
\text { Immune Modulatory Drugs and Other Treatments in COVID-19 } \\
\text { Patients - Sarilumab Trial - CORIMUNO-19 - SARI } \\
\text { (CORIMUNO-SARI) }\end{array}$ & $\begin{array}{l}\text { U. S. National Library of Medicine } \\
\text { ClinicalTrials.gov }\end{array}$ \\
\hline 4 & $\begin{array}{l}\text { Anti-il6 Treatment of Serious COVID-19 Disease with } \\
\text { Threatening Respiratory Failure (TOCIVID) }\end{array}$ & $\begin{array}{l}\text { U. S. National Library of Medicine } \\
\text { ClinicalTrials.gov }\end{array}$ \\
\hline
\end{tabular}

\section{Plasma de Paciente Convalescente}

O plasma humano é a parte líquida remanescente do sangue total após separação das frações celulares sanguíneas, é utilizado na produção de hemoderivados (ANDRADE et al., 2015). Os produtos derivados desse líquido possuem diversas aplicações, dentre elas a imunização passiva. O plasma de pacientes que sobreviveram a infecções prévias, pacientes convalescentes, e desenvolveram imunidade humoral contra o patógeno responsável pela doença em questão, é uma possível fonte de anticorpos específicos de origem humana (BURNOUF et al., 2014). Essa técnica objetiva promover uma imunização à curto prazo até que o indivíduo consiga desenvolver uma resposta imune ativa. Diante dessa evidência, estudos foram realizados para comprovar e viabilizar o plasma de pacientes convalescentes como terapia em doenças virais, assim como as que causaram os surtos de SARS-CoV (Síndrome Respiratória Aguda Grave), em 2002 (SOO et al., 2014) e MERS-CoV (Síndrome Respiratória do Oriente Médio), em 2012 (ARABI et al., 2016), ambas causadas por patógenos da mesma família do novo coronavírus, agente etiológico da COVID-19.

A terapia com plasma convalescente tem sido aplicada como prevenção e tratamento em diversas doenças infecciosas, destacando-se nas duas últimas décadas, como recurso terapêutico nas já mencionadas SARS e MERS, além da pandemia de H1N1 de 2009 com eficácia satisfatória. Em uma Metanálise (MAIRJENKINS et al., 2015) que incluiu 32 estudos de SARS por coronavírus e Influenza grave mostraram uma redução estatisticamente significativa nas chances de mortalidade, após o tratamento com o plasma, quando 
comparadas a um placebo ou à ausência de uma terapia. Apesar de as características virológicas e clínicas dessas doenças serem similares às da COVID-19, os potenciais riscos e benefícios da aplicação clínica desse tratamento ainda permanecem incertos (DUAN et al. 2020).

O contexto das pesquisas sobre a terapia pelo plasma convalescente não é ampla quando comparada a outros métodos, tendo em vista, principalmente, sua utilização em situações de crises ou surtos. Um estudo chinês realizado no hospital Third People na cidade de Shenzhen relatou a melhora no quadro clínico de cinco pacientes da COVID-19, esses apresentavam previamente uma insuficiência respiratória grave e recebiam ventilação mecânica. Entretanto, mais estudos precisam ser realizados para garantir a efetividade da terapêutica, visto que, essa intervenção não foi avaliada em um ensaio clínico randomizado, e os resultados no grupo de tratamento não foram comparados com os resultados de um grupo controle de pacientes, que não receberam a intervenção (SHEN et al., 2020; ROBACK e GUARNER, 2020).

Conforme apresentado na Quadro 2 do presente artigo, já existe grande quantidade de Ensaios Clínicos registrados, presentes no U.S. National Library of Medicine ClinicalTrials.gov, que buscam identificar de forma sistemática os efeitos, a eficácia e segurança da utilização do plasma de pacientes convalescente no tratamento contra o SARS-CoV-2.

Recentemente, em nota técnica a Agência Nacional de Vigilância Sanitária (ANVISA), autorizou no Brasil a pesquisa clínica com plasma de paciente convalescente (BRASIL, 2020).

Quadro 2. Ensaios Clínicos com Plasma Convalescente

\begin{tabular}{|c|c|c|}
\hline Ref. & Ensaios Clínicos Mencionados & Registro do Ensaio Clínico \\
\hline 1 & $\begin{array}{l}\text { Convalescent Plasma to Limit Coronavirus Associated } \\
\text { Complications }\end{array}$ & $\begin{array}{l}\text { U. S. National Library of Medicine } \\
\text { ClinicalTrials.gov }\end{array}$ \\
\hline 2 & $\begin{array}{l}\text { Convalescent Plasma for Patients With COVID-19: A Pilot Study } \\
\qquad \text { (CP-COVID-19) }\end{array}$ & $\begin{array}{l}\text { U. S. National Library of Medicine } \\
\text { ClinicalTrials.gov }\end{array}$ \\
\hline 3 & $\begin{array}{c}\text { Anti-SARS-CoV-2 Inactivated Convalescent Plasma in the } \\
\text { Treatment of COVID-19 }\end{array}$ & $\begin{array}{l}\text { U. S. National Library of Medicine } \\
\text { ClinicalTrials.gov }\end{array}$ \\
\hline 4 & $\begin{array}{l}\text { Investigating Effect of Convalescent Plasma in the Treatment of } \\
\qquad \text { COVID-19 }\end{array}$ & $\begin{array}{l}\text { U. S. National Library of Medicine } \\
\text { ClinicalTrials.gov }\end{array}$ \\
\hline 5 & $\begin{array}{c}\text { Convalescent Plasma for Patients With COVID-19: A Randomized, } \\
\text { Open Label, Parallel, Controlled Clinical Study (CP-COVID-19) }\end{array}$ & $\begin{array}{l}\text { U. S. National Library of Medicine } \\
\text { ClinicalTrials.gov }\end{array}$ \\
\hline 6 & $\begin{array}{c}\text { Efficacy and Safety Human Corona virus Immune Plasma (HCIP) } \\
\text { vs. Control (SARS-CoV-2 Non-immune Plasma) Among Adults } \\
\text { Exposed to COVID-19 (CSSC-001) }\end{array}$ & $\begin{array}{l}\text { U. S. National Library of Medicine } \\
\text { ClinicalTrials.gov }\end{array}$ \\
\hline
\end{tabular}




\section{Vacinas}

O mecanismo de ação da vacinação é baseado na geração de uma resposta imune ativa própria, que fornecerá proteção contra agentes ou toxinas patogênicas. Após a inserção de antígenos específicos que constituem a vacina no organismo, os mecanismos que geram a memória imunológica são a ativação de subtipos de linfócitos $\mathrm{T}$, especialmente no combate a antígenos intracelulares (TH1 e linfócitos $\mathrm{T}$ citotóxicos), e a imunidade humoral, executada em sua etapa final pelos linfócitos B (VETTER et al., 2017). Estes últimos, após terem sido ativados diretamente pelos antígenos, estimulados e direcionados pelos linfócitos $\mathrm{T}$ auxiliares, passam a expandir seus clones, transformarem-se em plasmócitos e produzir imunoglobulinas com alta afinidade para seus determinantes imunogênicos, sendo que algumas dessas células- filhas tornam-se células de memória, para atuarem com maior rapidez em uma segunda infecção. Vale ressaltar que as células $\mathrm{T}$ auxiliares também possuem a capacidade de se transformar em células de memória nesse processo. (CLEM, 2011).

Dessa forma, as vacinas podem ser definidas como "uma suspensão de microrganismos patogênicos, mortos ou atenuados, introduzidas em um organismo a fim de provocar a formação de anticorpos contra determinado agente infectante" (VETTER et al., 2017). Tratando-se de vacinas virais, nosso foco devido à ascensão do COVID-19, podemos classificá-las em:

\section{1) Vacinas de vírus vivos atenuados}

Vacinas deste tipo são feitas de modo a enfraquecer ou atenuar os microorganismos utilizados (os quais podem ser vírus ou bactérias), diminuindo, assim, sua virulência. Desse modo, obtém-se uma alta resposta de proteção ao hospedeiro - dado que se mantém sua imunogenicidade - sem que ocorra a doença de fato, em pessoas imunocompetentes. As vacinas virais são consideradas como um dos tipos mais efetivos, pois induzem à imunidade específica duradoura. Pode-se citar como exemplos: febre amarela, sarampo e poliomielite. Muitas quando aplicadas na infância, por vezes, são suficientes e não há necessidade de reaplicação, dado que sua função protetora se perpetua por toda vida (ABBAS, 2018).

Uma das complexidades acerca das vacinas virais é a necessidade de se obter um organismo vivo capaz de ser infectado e produzir partículas virais atenuadas. Assim, o método mais utilizado para produção de vírus atenuados é a passagem repetida em cultura celular. Muitas vacinas virais tradicionais como a febre amarela - são cultivadas em ovos férteis de galinha (ROBINSON, 2016). A atenuação pode ser feita pelo cultivo do vírus in vitro, em células de outras espécies animais, nas quais o vírus sofre mutação para poder infectar a célula da cultura, passando a não expressar mais os fatores de virulência para células humanas. Por isso, as vacinas com vírus atenuados não podem ser administradas em pacientes imunossuprimidos, ou pacientes crônicos que fazem uso de imunossupressores, pois a atenuação pode ser revertida nesses pacientes. Justamente, pela necessidade de uma célula viva para sua expansão, os vírus podem ter estabilidade limitada uma vez que as células são removidas.

A grande questão acerca deste tipo de vacina é referente a sua segurança. É possível que, mesmo feita a partir do vírus atenuado, ela possa induzir a doença em indivíduos imunocompetentes? O grande exemplo é a vacina contra a poliomielite que, em casos raros relatados, houve uma reativação viral e desenvolvimento da doença. Para este dilema, muitos apontam como solução a utilização de vírus mortos. 


\section{2) Vacinas de vírus inativado}

Nesse caso, por conter vírus inativados por métodos químicos (formol, detergentes, aquecimento), esse tipo de vacina oferece mais segurança em relação àquelas que contêm vírus atenuado, não havendo risco de multiplicação do agente viral. No entanto, as vacinas de vírus inativado induz uma imunidade menos duradoura, sendo necessário frequentemente mais de uma dose, ou reaplicação da vacina com o decorrer dos anos. Novas tecnologias, como o uso da tecnologia do DNA recombinante para o preparo em larga escala, vêm sendo aplicadas no desenvolvimento de vacinas inativadas (ROBINSON, 2016).

A vacina da influenza, por exemplo, representa um caso de vacina por vírus inativado, sendo administrada anualmente àqueles que compõe o grupo de risco para desenvolvimento de quadro clínico mais grave de infecção pulmonar (idosos, imunossuprimidos, profissionais de saúde).

\section{3) Vacinas de vírus vivos envolvendo vírus recombinantes}

São vacinas produzidas por técnicas de engenharia genética que permitem a produção de antígenos sem a utilização do organismo infeccioso nativo. De modo geral, há a introdução de genes que codificam antígenos microbianos em um vírus não citopático. Tal vírus constitui, portanto, uma fonte de antígeno, no indivíduo, ao ser inoculado e induz respostas imunes protetoras. Assim como a utilização de vírus vivos atenuados, as vacinas recombinantes deste tipo levantam uma questão de segurança: mesmo não sendo patogênicos, os vetores virais, que carregam genes para produção de antígenos, podem induzir respostas de CTL (células T citotóxica) e resultar na morte de células hospedeiras infectadas? (ABBAS, 2018).

\section{4) Vacinas de DNA (gênicas)}

Nesse método, inoculam-se fragmentos genômicos de células contendo DNA viral diretamente no indivíduo a ser imunizado. Tais fragmentos se multiplicam nas células do hospedeiro e formam os anticorpos necessários para proteção do indivíduo. Essa técnica tem como vantagem a apresentação dos antígenos ao sistema imune em sua forma nativa, sem manipulação ou modificações desses imunógenos (SCHATZMAYR, 2003). No entanto, a resposta imune tende a ser ineficaz, acredita-se no eventual potencial de ativação de respostas citotóxicas (DINIZ e FERREIRA, 2010). Vírus respiratórios, como o da influenza, apresentaram uma resposta adequada nos experimentos iniciais.

A formulação de vacinas deve ser desenvolvida de modo a alcançar um formato que maximize sua estabilidade e permita a eficácia de entrega e distribuição. As vacinas, de modo geral, são compostas por um líquido de suspensão (usualmente água destilada ou solução salina fisiológica), conservantes, pequena quantidade de antibióticos para evitar a proliferação bacteriana e estabilizadores (em casos de vacinas de vírus vivo atenuado) (SCHATZMAYR, 2003). Em algumas vacinas, também são adicionados compostos adjuvantes (sais de alumínio, hidróxido ou fosfato), que amplificam o poder imunogênico da vacina por reter o antígeno no local da aplicação e induzirem uma resposta inflamatória, que favorece a fagocitose, o processamento e a apresentação do antígeno, pelas Células Dendríticas aos linfócitos $\mathrm{T}$, nos órgãos linfóides secundários e, consequentemente, a ativação dos linfócitos B, que reconheceram o antígeno drenado para esses órgãos.

Após a elaboração, o produto desenvolvido é despejado em seringas ou frascos e supervisionado em 
condições rigorosas que objetivam prevenir quaisquer contaminações. O controle de qualidade ocorre neste ponto, utilizando critérios de segurança, potência, pureza, esterilidade e outros relacionados ao produto específico (ROBINSON, 2016).

O desenvolvimento de vacinas é complexo, altamente dependente de tecnologia e de investimentos em pesquisa e desenvolvimento experimental. Além do investimento financeiro elevado e da qualificação científica e técnica, também envolve questões éticas e legais que variam em cada país. O protótipo da vacina deve obter sucesso em modelos experimentais com animais, e nas fases pré-clínica e clínica, onde são testados a segurança, imunogenicidade e eficácia, podendo levar vários anos até ser aprovado para uso (ARMÔA, 2009). No Brasil, grande parte do desenvolvimento vacinal é atribuído aos laboratórios do Instituto Butantan (SP) e Bio-Manguinhos (RJ).

Com o aumento exponencial do número de casos de SARS-CoV-2 e sem uma terapêutica estabelecida para tratá-los, o desenvolvimento de uma vacina eficaz contra o coranavírus 2 é urgente e ocorre em ritmo acelerado em diferentes partes do globo, com 44 vacinas candidatas em diferentes fases de testes listadas pela Organização Mundial da Saúde (OMS). Sendo duas na fase 1 e as demais na fase pré-clínica.

Um ensaio clínico em fase 1 (Quadro 3. Ref.1), cooperação entre o Instituto Nacional de Alergia e Doenças Infecciosas dos EUA (NIAID) e a Companhia de Biotecnologia Moderna Inc., testa a vacina chamada mRNA-1273. O coronavírus tem formato esférico com projeção de espículas em sua superfície, Moderna já trabalhava na produção de uma vacina contra a MERS com alvo nessas espículas e após a divulgação da sequência genética da SARS-CoV-2, selecionaram uma sequência para estabilizar a proteína da espícula no mRNA para a confecção da mRNA-1273. Nesse estudo, os participantes receberam duas doses da vacina, em injeção intramuscular no músculo deltóide, com 28 dias entre cada dose, divididos em três grupos com administração de dosagem diferentes. Com o objetivo de verificar a segurança e reatogenicidade deste medicamento.

Outra pesquisa é desenvolvida pela Instituto de Biotecnologia da Academia Militar de Ciências Médicas da China e pelo CanSino Biologics Inc (Quadro 3. Ref. 2). Encontra-se em fase clínica 1, testando vacina com vetor adenoviral tipo 5 quanto a segurança, a imunogenicidade e a reatogenicidade. Serão feitos três grupos com dose-escalada, com o participante recebendo uma dose única de acordo com o seu grupo.

Há ainda outro ensaio para testar uma vacina com vetor adenovírus (ChAdOx1) desenvolvido pela Universidade de Oxford (Quadro 3. Ref. 3). A ChAdOx1 provoca uma boa resposta imune de uma única dose e não é de um vírus replicado, aumentando sua segurança. A estrutura do ChAdOx1 possui a sequência genética da espícula da superfície do vírus. Esse ensaio terá comparação entre grupo placebo e que recebeu a terapia e está em período de recrutamento de participantes.

No Brasil, o Laboratório de Imunologia do Instituto do Coração (Incor), da Faculdade de Medicina, da Universidade de São Paulo, está desenvolvendo uma vacina com VLP, ou seja, a partir de uma partícula semelhante ao coronavírus, mas sem o material genético dele. Ainda não se iniciou os testes em animais ou humanos (JORNAL USP, 2020).

Os ensaios mencionados no texto estão listados na Quadro 3. 
Quadro 3. Ensaios Clínicos com Vacinas

\begin{tabular}{|c|c|c|}
\hline Ref. & Ensaios Clínicos Mencionados & Registro do Ensaio Clínico \\
\hline 1 & $\begin{array}{l}\text { Safety and Immunogenicity Study of 2019-nCoV Vaccine } \\
\text { (mRNA-1273) for Prophylaxis SARS CoV-2 Infection }\end{array}$ & $\begin{array}{c}\text { U. S. National Library of Medicine } \\
\text { ClinicalTrials.gov }\end{array}$ \\
\hline 2 & $\begin{array}{l}\text { A phase I clinical trial for recombinant novel coronavirus } \\
\text { (2019-COV) vaccine (adenoviral vector) }\end{array}$ & Chinese Clinical Trial Registry \\
\hline 3 & A study of a Candidate COVID-19 Vaccine (COV001) & $\begin{array}{l}\text { U. S. National Library of Medicine } \\
\text { ClinicalTrials.gov }\end{array}$ \\
\hline 4 & $\begin{array}{l}\text { A phase I/II trial of candidate COVID-19 vaccine } \\
\text { (COV001) }\end{array}$ & National Institute for Health Research \\
\hline
\end{tabular}

\section{CONCLUSÃO}

O COVID-19 tornou-se uma ameaça global desde que surgiram relatos em dezembro de 2019. Por ser uma doença de alta transmissão e manifestações clínicas variáveis, muitas de acordo com cada organismo, inúmeras medidas preventivas foram tomadas. Dentre essas, o que se almeja mundialmente é a criação de uma vacina, que estabeleça uma memória imune para a proteção e prevenção de infecções futuras.

A corrida terapêutica para o COVID-19 já começou, empresas farmacêutica, cientistas, bioquímicos e vários investidores estão nesse torneio que visa uma resposta à população mundial. Enquanto vacinas inativadas ainda devem ser testadas, abordagens alternativas incluem vacinas vivas atenuadas, vacinas de subunidades e vacinas à base de vetores. Todos esses merecem mais investigações e testes em animais.

Com isso, novos estudos estão sendo promissores em relação a criação de novas vacinas, mas enquanto não há essa possibilidade devemos nos manter vigilantes, realizar a higienização diária, cuidados em casa e esperar a solidificação de pesquisas científicas quanto às medidas profiláticas intervencionistas.

\section{AGRADECIMENTOS}

Todos os autores declararam não haver qualquer potencial conflito de interesses referente a este artigo.

\section{REFERÊNCIAS}

ABBAS, A.K. Cellular and Molecular Immunology. 9. ed. : Elsevier, 2018. 608p.

ANDRADE, S.B.; ROLIM, L.A.; NETO, P.J.R. Estudo da estabilidade do plasma humano fresco congelado destinada a produção de hemoderivados. Rev. Bras. Farm. 96 (1): 1005 - 1021, 2015.

ARMÔA, G.R.G. Desenvolvimento de vacinas na era pós genômica e biossegurança. Biossegurança de OGM: uma visão integrada. Rio de Janeiro: Publit Soluções Editoriais, p. 220-238, 2009.

ARABI, Y.M.; HAJEER, A.H.; LUKE, T.; et al. Feasibility of Using Convalescent Plasma Immunotherapy for MERS-CoV Infection, Saudi Arabia. Emerging infectious diseases, 22(9), 15541561, 2016.

BRASIL. MINISTÉRIO DA SAÚDE. SECRETARIA DE VIGILÂNCIA EM SAÚDE. Departamento de Vigilância Epidemiológica. Manual dos centros de referência para imunobiológicos especiais / Ministério da Saúde, Secretaria de Vigilância em Saúde. 
Departamento de Vigilância Epidemiológica. Brasília: Ministério da Saúde, 2006

BRASIL. MINISTÉRIO DA SAÚDE. SECRETARIA DE CIÊNCIA, TECNOLOGIA E INSUMOS ESTRATÉGICOS. Departamento de Assistência Farmacêutica e Insumos Estratégicos. Formulário terapêutico nacional 2010: Rename 2010/Ministério da Saúde, Secretaria de Ciência, Tecnologia e Insumos Estratégicos, Departamento de Assistência Farmacêutica e Insumos Estratégicos. - 2. ed. Brasília: Ministério da Saúde, 2010.

BRASIL, Anvisa. Nota Técnica No. 19/2020-SEIGSTCO-DIRE1-ANVISA. 03 de abril de 2020.

BURNOUF, T.; SEGHATCHIAN, J. Ebola virus convalescent blood products: where we are now and where we may need to go. Transfus Apher Sci. 2014; 51(2):120-5.

CASADEVALL, A.; PIROFSKI, L. The convalescent sera option for containing COVID-19. Journal of Clinical Investigation, v. 130, n. 4, p. 1545-1548, 2020.

CENTERS FOR DISEASE CONTROL AND PREVENTION. People who are at higher risk for severe illness, 2019.

CLEM, A.S. Fundamentals of vaccine immunology. Journal Of Global Infectious Diseases, v. 3, n. 1, p.73-78, 2011.

DINIZ, M.O., FERREIRA, L.C.S. Biotecnologia aplicada ao desenvolvimento de vacinas. Estud. av., v. 24, n. 70, p. 19-30, 2010.

GUAN, W.-J.; NI, Z.-Y.; HU, Y.; et al. Clinical Characteristics of Coronavirus Disease 2019 in China. New England Journal of Medicine, p. NEJMoa2002032, 2020.

DUAN, K.; LIU, B.; LI, C.; et al. The feasibility of convalescent plasma therapy in severe COVID-19 patients: a pilot study. MedRxiv, p. 2020.03.16.20036145, 2020

KRAEMER, M. U. G.; YANG， C.-H.; GUTIERREZ, B.; et al. The effect of human mobility and control measures on the COVID-19 epidemic in China. Science, v. 4218, n. March, p. eabb4218, 2020.
LI, Q.; GUAN, X.; WU, P.; WANG, X.; ZHOU, L.; TONG, Y.; REN, R.; LEUNG, K.; LAU, E.H.; WONG, J.Y. Early Transmission Dynamics in Wuhan, China, of Novel Coronavirus-Infected Pneumonia. New England Journal Of Medicine, v. 382, n. 13, p.11991207, 26 mar. 2020.

LUKE, T. C.; CASADEVALL, A.; WATOWICH, S. J.; et al. Hark back: Passive immunotherapy for influenza and other serious infections. Critical Care Medicine, v. 38, n. SUPPL. 4, p. e66-e73, 2010.

MANIS, J.P. Overview of therapeutic monoclonal antibodies. Up-To-Date, 3 out. 2019.

MAIR-JENKINS, J.,; SAAVEDRA-CAMPOS, M.; BAILLIE, J.K.; CLEARY, P., KHAW, F.M., LIM, W. S., MAKKI, S.; ROONEY, K.D.; NGUYEN-VANTAM, J.S.; BECK, C.R.; \& Convalescent Plasma Study Group (2015). The effectiveness of convalescent plasma and hyperimmune immunoglobulin for the treatment of severe acute respiratory infections of viral etiology: a systematic review and exploratory metaanalysis. The Journal of infectious diseases, 211(1), 80-90.

ZHOU, F.; YU, T.; DU, R.; et al. Clinical course and risk factors for mortality of adult inpatients with COVID-19 in Wuhan, China: a retrospective cohort study. The Lancet, v. 395, n. 10229, p. 1054-1062, 2020.

MOSER, M.; LEO, O. Key Concepts in Immunology. Vaccine, v. 28, Suppl 3, C2-C13, ago. 2010.

PROMPETCHARA, E.; KETLOY, C.; PALAGA, T. Immune responses in COVID-19 and potential vaccines: Lessons learned from SARS and MERS epidemic. Asian Pacific Journal of Allergy and Immunology. 38. 2020.

ROBACK J.D.; GUARNER J. Convalescent Plasma to Treat COVID-19: Possibilities and Challenges. JAMA. Published online. March 27, 2020.

ROBINSON, J.M. Vaccine Production: Main Steps and Considerations. The Vaccine Book, p.77-96, 2016. Elsevier.

ROTHAN, H. A.; BYRAREDDY, S. N. The epidemiology and pathogenesis of coronavirus disease (COVID-19) outbreak. Journal of Autoimmunity, p. 102433, 2020. 
SCHATZMAYR, H.G. Novas perspectivas em vacinas virais. Hist. Cienc. Saúde-Manguinhos, Rio de Janeiro, v. 10, supl. 2, p. 655-669, 2003.

SHEN, C.; WANG, Z.; ZHAO, F.; YANG, Y.; LI, J.; YUAN, J.; WANG, F.; LI, D.; YANG, M.; XING, L. Treatment of 5 Critically Ill Patients With COVID-19 With Convalescent Plasma (epub-ahead-of-print). JAMA, 27 Março de 2020.

SOO, Y.O.Y., CHENG, Y., WONG, R., HUI, D.S., LEE, C.K., TSANG, K.K.S., NG, M.H.L., CHAN, P., CHENG, G.; SUNG, J.J.Y. Retrospective comparison of convalescent plasma with continuing high-dose methylprednisolone treatment in SARS patients. Clinical Microbiology and Infection, 10: 676-678. 2014.

VETTER, V. Understanding modern-day vaccines: what you need to know. Annals of Medicine, v. 50, n. 2, p.110-120, 2017.

WANG, C.; LI, W.; DRABEK, D.; et al. A human monoclonal 1 antibody blocking SARS-CoV-2 infection. BioRxiv, p. 2020.03.11.987958, 2020.

WANG, Y.; WANG, YUYI; CHEN, Y.; QIN, Q. Unique epidemiological and clinical features of the emerging 2019 novel coronavirus pneumonia (COVID-19) implicate special control measures. Journal of Medical Virology, p. jmv.25748, 2020.

WORLD HEALTH ORGANIZATION (WHO). Coronavirus disease 2019 (COVID-19) Situation Report - 77. 2020.

WORLD HEALTH ORGANIZATION (WHO).

DRAFT landscape of COVID-19 candidate vaccines.

Disponível em:

<https://www.who.int/blueprint/priority-diseases/keyaction/novel-coronavirus-landscape-ncov.pdf?ua=1 $>$. Acesso em: 6/4/2020b.

WU, F.; ZHAO, S.; YU, B.; et al. A new coronavirus associated with human respiratory disease in China. Nature, v. 579, n. 7798, p. 265-269, 2020.

Vacina em desenvolvimento na USP usa partícula semelhante ao coronavírus. Jornal USP. <jornal.usp.br/?p=308104>, 2020.

CASADEVALL, A.; PIROFSKI, L. The Ebola epidemic crystallizes the potential of passive antibody therapy for infectious diseases. PLoS Pathog. 2015;11(4):e1004717. Published 2015 Apr 23.
MCINTOSH, K. Coronavirus disease 2019 (COVID19). Up To Date, [s. l.], 31 mar. 2020. 